\title{
Temporality in Organization Studies: Implications for Strategic Project Management
}

\author{
Christopher Biesenthal ${ }^{*}, 1,4$, Shankar Sankaran ${ }^{1,4}$, Tyrone Pitsis ${ }^{2}$ and Stewart Clegg ${ }^{1,2,3}$ \\ ${ }^{I}$ Centre for Management and Organisation Studies, University of Technology Sydney, Australia \\ ${ }^{2}$ Newcastle University Business School, Newcastle, UK \\ ${ }^{3}$ Nova School of Economics and Business, Lisboa, Portugal \\ ${ }^{4}$ School of the Built Environment, University of Technology, Sydney, Australia
}

\begin{abstract}
Project managers require temporal skills and the ability to improvise when linear assumptions confront the complexities of managing projects within a context of strategic calculation. While the management and organization (MOS) literature emphasizes the importance of temporal skills for managing uncertainty, ambiguity and complexity, a dearth of project management literature contributes to this discussion. By reviewing literature on time in MOS and linking it to the field of project management we seek to make an initial bridge of this gap and argue that in order to improvise project managers need temporal skills. Project management practitioners and researchers work with assumptions of what constitutes normal time and linearity in projects, despite the variety of situations and events faced in projects. Practitioners, students and researchers in project management need to develop more sophisticated temporal skills to deal with a variety of projects, situations and events strategically.
\end{abstract}

Keywords: Improvisation, literature review, projects, strategy-as-practice, temporality, time.

\section{INTRODUCTION}

Project management's complexity, variety and uses have increased considerably over the past two decades. Despite the prominence of temporal issues in practice, there is a shortage of research in the project management literature on aspects of time other than clock time. Hardly surprising perhaps: much social science research has for most of its history been characterized by a rudimentary attention to time and time-related issues, yet they are central to every aspect of organization and every project. Daily and weekly working hours, schedules, opening and closing dates, deadlines, rhythmic cycles of individual and collective activity, lead times and much more are the stuff of everyday management anxiety and attention. Scheduling and synchronizing activities are a daily challenge. Events throw up delays and create time-stress.

A number of recent publications have increased awareness of the necessity to incorporate time in theoretical models and research designs [1-4]. Earlier research on time previously unrecognized is now valued $[5,6]$ while temporality is increasingly coming into focus [7-10]. These contributions challenge the mundane concept of time as just something that ticks away on a clock. Depending on how they deal with the objective and psychological dimensions of time project managers will manage more or less effectively. Sophisticated project managers understand that time in all its

*Address correspondence to this author at the Centre for Management and Organisation Studies, University of Technology Sydney, Australia;

Tel: +61 29514 8950; E-mail: Christopher.Biesenthal@uts.edu.au forms is socially constructed; sophisticated project management researchers should also understand that debate over views of time is socially constructed.

Projects are typically socially constructed as “...a temporary endeavour undertaken to create a unique product, service or result" [11]. Temporality, and how it is constructed, defines the lifespan of a project and thus its strategic being as an organizational entity in a particular configuration. Time is a main performance measure in projects [12] and thus one of the factors that is used to construct what constitutes productivity and project success. Time is a strategic resource [13], used a s a social construct to try and ensure projects are accomplished 'in time' and 'on time', thus having a major impact on the way project managers deliver projects.

In the remainder of this paper we first provide a literature review of temporal issues proposed in the MOS literature that are relevant for project managers. Next, we describe time in practice, which provides us with a link to time in project management. Further, we highlight how projects are different to traditional organizations and how they have an impact on the social construction of temporal skills and practices. Last, we use the concept of improvisation to provide a concept for temporal skills in project management, and conclude with some implications for project management and project managers.

Time is an important aspect of our daily life as we perform our routines, rituals and rationalities. Time, in its constant fluidity and flux, enables us to put things in perspective: time for each of us and for each of our projects 
is finite but infinite in its constant potential for specification and refinement. Great projects can take many lifetimes: huge cathedrals, major hydraulic projects and hundred years' wars are examples. We create time scapes of past, present and future in which the interplay between the three tenses guides our actions in the present moment. While we experience time in the present, our actions and sense making is based both on past experiences and projected futures; in other words, on knowledge accumulated in the past $[14,15]$ because we can only imagine futures based on what we have learned - not what we have yet to discover. Accordingly, Butler [16] classifies the past in terms of codes learned from past actions [17]. Coded recollections form memory. Memories play a vital role in how we picture the future. On the other hand, the future tense represents congruence and horizons, as it is "the process of understanding forward by understanding back, and making choices on the basis of that understanding" [16]. This reflective sense making of the different tenses enables organizational forecasting, predicting and planning [18].

\section{TIME IN MOS}

Time has long been a more or less explicit research lens for MOS [19]. In addition to traditional lenses such as strategy, politics, design and culture, time offers an alternative way of making sense of organizations [2]. Temporality research in MOS has come a long way since Frederick Taylor proposed his scientific notion of time, in which the clock presented an objective measure for efficiency, productivity and performance, and thus transformed time into a resource for organizing the political economy of men and machines $[13,20]$. No dominant or absolutist notion of time can explain the multiplicity of times experienced in organizational life. Organizations' increasing complexity [20, 21], professionalization [22], and globalization [23] make temporal reckonings acute, especially as they differ between and within societies and consequently in organizations $[13,16,20]$. As a result, several dichotomies of time have emerged in the organizational literature [24]. At the core of these dualisms is the distinction between an objective and subjective perception of time [25]. In the following section, we will highlight two debates in temporality research in organizations, namely, clock versus event time and linear versus cyclical time.

\section{CLOCK VERSUS EVENT TIME}

The first major dichotomy in temporality research is the distinction between clock time and event time [26]. At the core of this debate is the Greek distinction between chronos and kairos, which represents the difference between chronological and non-chronological time [19]. While chronos stands for objective, homogeneous, measurable (i.e., 'planned' causal recurring time), Newtonian time, kairos describes subjective, heterogeneous, experienced, Einsteinian time (i.e., emergent opportunistic, usually one-off time) [19]. Beginning with Taylor's Scientific Management [27], the notion of chronological time became prominent and shaped the perception of time in our modern industrial society. Time was closely linked to the invention of the clock and used as a measure of efficiency, productivity and performance $[13,20]$. Time conceived as efficient clockwork is consistent with an atomic or mechanical view of the world [28], having the Greek notion of chronos at its centre. Chronos perceives time as objective and quantitative, able to be measured in terms of the timing and duration of actions [26]: In other words, clock-based time is "the chronological, serial time of succession [...] time measured by the chronometer not by purpose" [28]. Clock time was dominant in temporal research in MOS until the mid 1980s. With the increasing complexity of organizational life, however, Taylor's notion of clock-based time lost its dominant status [20, 21].

In 1985, Clark added a second dimension to the perception of time by emphasising the importance of event time in organizations, in which "[organizational] life is framed by meaningful events, including those that are related to seasonal variations" [13]. Named after the Greek god of opportunity, kairos describes "the human and living time of intentions and goals [...] the time not of measurement but of human activity, of opportunity" [28]. Event time as an additional time perspective helps researchers to gain a deeper and richer understanding of organizational life, and is often described as qualitative time [29]. In this view, "[t] ime is in the events, and events are defined by organizational members" [30]. Hence, event time is neither fixed nor regular; it is rather a more dynamic concept of time that varies by perception and norms [26]. As Roe [19] stresses, the opposing views of clock and event time are 'competing camps' in the field of MOS. ${ }^{1}$

\section{LINEAR VERSUS CYCLICAL TIME}

The second major dichotomy of time in organizational research deals with the distinction between linear and cyclical time [21]. The main differentiator between the two perspectives is their emphasis on the past tense, and the consequences for organizational actions. Linear time is the dominating time perception in the Western countries [31,32]. Hence, linear time is most prominently linked to clock time and represents a seemingly objective understanding of time in organizations. In this view, time is understood as a limited organizational resource that - just as any other resource - is subject to planning and allocation, making adequate time management a crucial aspect of daily organizational work. Seeing time as a linear concept implies that the past is never repeated and is always different from the future [32, 33]. The main organizational focus is on the future, while the importance of the past is diminished [32]. In other words, organizations only use the past to define, predict and plan the future strategy, based on which they decide managerial actions in the present. The main focus in linear time management is the accurate prediction of future contingencies in order to allocate organizational resources effectively and efficiently, something with which time, when perceived as a linear construct, obliges. In such perspectives, the major enemies of time and rationality are events and the uncertainties thrown up by these occasions for recursive contingency [34].

\footnotetext{
${ }^{1}$ It should be mentioned at this stage that event-time had already existed in the social sciences. For instance, early works on agriculture studies focused on "irregular event-based patterns" (Bluedorn and Denhardt 1988). Max Weber (1947) and other social theorists emphasised social changes contributing a more "rigidly organized and scheduled patterns", which they related to the elective affinities existing between protestant forms of calculation and the growth of capitalism and industrialization.
} 
When perceiving time as cyclical, the past plays a crucial role: time is seen as a recurring pattern, which enables predictions and planning conceptually. Hence, investigating and analysing past routines and action patterns is an important aspect in organizations that use a cyclical approach to time. Organizational action is based on understanding of past performed practices rather than future predictions since the future is merely seen as a reoccurring past $[32,35]$. In this view, time is generally perceived as "being a socially constructed set of stages" [32]. Organizational actions (e.g. resources allocation) are therefore linked to certain stages in the organizational cycle, such as the project lifecycle. Organizations that operate within a cyclical temporality are, however, subject to a variety of cycles that have to be synchronized due to potentially different sequences, paces and rhythms of those work cycles.

\section{ENTRAINMENT}

Organizational cycles emerge on the basis of external and internal influences, such as changes in market demand or restructuring of internal processes. It is therefore crucial for organizations to align and account for the different cycles addressed in the entrainment literature [25]. Entrainment is defined as "the adjustment of the pace or cycle of one activity to match or synchronize with that of another" [36]. A cycle represents the single completed period of a continuously repeated temporal phenomenon [36, 37]. The adjustment of the cycle can occur in any temporal parameter of a certain activity, such as phase, periodicity or pace [38]. Pace or tempo entrainment scans the alignment of speed, while phase entrainment examines the synchronization of cycles [38]. For instance, in project management, entrainment occurs when multiple firms adjust their activities and processes within their internal project lifecycle to make sure the project is delivered within the overarching lifecycle. Entrainment is generally guided by pacers or temporal cues, which are called zeitgebers [39]. Based on the nature and frequency of the zeitgeber, the cycles develop a synchronized rhythm that naturally establishes a temporal hierarchy that helps organizations to coordinate their practices and processes. While entrainment is mainly concerned with organizational cycles, Orlikowski and Yates [25] show that this view of time acknowledges both clockbased and event-based cycles (for example, quarterly or annual budgeting periods and seasonal sports activities).

Consequently, the connection between the four main components of temporality - clock time, event time, cyclical time and linear time - is ambiguous. More precisely, some authors [19] link clock-based time to linearity, and event time to work cycles, while others [40] argue for the opposite combination. Despite this indefinite relationship, these four pillars of time build the foundation for the current debates on temporality in management and organization studies. Due to this indefinite relationship it can be concluded that time is not a constant but is rather a variable in organizational life [13]. Furthermore, the two views on time are compatible in practice, meaning they can be combined in any possible way [39]. Hence, it makes sense to investigate time in organizations from a practice perspective in order to transcend the dualist discussions around the temporal dimensions. Table $\mathbf{1}$ provides an overview of the temporal concepts described so far.

\section{TIME IN PRACTICE}

In practice, the different temporal perspectives are not quite as clear-cut as described in the literature. Organizations use different temporal structures in different parts of the business (organizational level vs project level). As Orlikowski and Yates [25] illustrate, temporal structures in organizations can be both clock-based and event-based as the discrete separation often collapses. In organizational life people organize their activities in terms of both clock time and event time in order to meet the requirements of particular tasks. In a similar fashion, cyclical structures overlap with linear temporal approaches in organizational practice. For instance, organizational action is linked to linear time, whereas the strategic planning of organizational activities is associated with cyclical time [18]. This implies that different times occur in different parts of the organization serving a practical purpose for the particular business unit, making time a socially constructed tool that helps organizations to manage their operations successfully. Moreover, neither of the temporal approaches can generally be claimed to be more salient than the other without referring to a specific contextual application.

Focusing on practice allows us to move beyond discussions about temporal perspectives and see time as a practical tool used to organize organizational activities. Further, it allows us to investigate the concept of time in practice unconditionally, following Orlikowski and Yates [26], who propose the following practice-based perspectives of time:

- First, time is reflectively constituted by human action, which stands in contrast to the competing perception

Table 1. Summary of temporal concepts introduced (adapted from $[19,39,25]$ ).

\begin{tabular}{|c|l|}
\hline Term & \multicolumn{1}{|c|}{ Definition } \\
\hline \hline Chronos & Objective, homogeneous, measurable, Newtonian time, (or Clock time) \\
\hline Kairos & Subjective, heterogeneous, experienced, Einsteinian time (or event time) \\
\hline Linear time & Linked to clock time and represents an objective understanding of time in organizations as a limited organizational resource \\
\hline Cycle time & Time is seen as a recurring pattern, which enables predictions and planning conceptually based on the past. \\
\hline Entrainment & The process of adjusting pace or cycle of one activity to synchronize with another \\
\hline Zeitgeber & Pacers or temporal cues that guide entrainment \\
\hline
\end{tabular}


of time as being either absolute and objective or relative and socially constructed.

- Second, the experience of time - instead of being concerned with dichotomies such as the clock/event division - is grasped through human practices that both produce temporal structures (e.g. project schedules, clocks) and act based on them.

$\bullet$

Third, practice-based studies emphasize the importance of the organizational actor who actively experiences and practices within the given temporal structure. Hence, the actor is seen as an active component of the organization's temporal reality as he/she acts upon it but has also the ability to modify certain temporal aspects through practices (e.g. casual Friday).

In conclusion, as seen from the discussion above, time and temporality are well-discussed concepts in the organizational literature. The project management literature has, however, not yet established a substantial body of knowledge about the diverse ways in which time is used in practice [41] as well as in normative theory, such as PMBOK. In the following section we will provide an overview of time in project management.

\section{TIME IN PROJECT MANAGEMENT}

Project management practice favors clock time or chronos as a simple tool for 'managing time'. To meet project deadlines, clock time, is predominant in the project management literature as a knowledge area that project managers should master, a key competency that they should possess $[11,42]$. Theoretically, the project management literatures use lifecycles as a way to conceptualize project work, which indicates a particular focus on cyclical time [11]. The field emphasizes planning and predictions, assuming that projects can be managed in an objective manner, based on past events and objective tools and techniques with which to plan and predict the work required to deliver a project successfully. In addition, time is traditionally used as a performance measure, as summarized in the 'iron triangle' [43], which classifies time, cost and scope as critical to project success. Project cost and time are also closely interrelated in measuring project performance in the Earned Value Method used in projects. In other words, project managers and project organizations value time as a resource and as a performance measure that has a major impact on the execution of projects and the financial outcomes. Due to this objectified emphasis, project management research has predominantly emphasized chronos and neglected kairos or social time [44].

Some recent literature on project management has started to look at other aspects of time that project managers should be aware of in order to manage projects strategically [45]. Rämö [46] points out that while clock time or chronos helps in 'doing the right thing' and being efficient, a kairic understanding of time could help in 'doing things at the right time' and being effective as well. Rämö [46] argues that project managers, as opposed to functional managers, often have to deal with unplanned situations and take impromptu decisions. A broader view of time also helps project managers to be strategic in taking advantage of 'windows of opportunity' in projects. A pure focus on project efficiency based only on clock time could also restrain innovativeness and make project managers insensitive to identifying changing situations as they occur.

Dille and Söderlund [44] point out the importance of temporal issues that arise in inter-institutional projects. They point out that macro cycles set by dominant players or situations in such projects act as time givers (zeitgebers), to which other organizations in the project have to adapt; such times can be set by industry leaders or government entities through budget or audit cycles. These macro cycles command the tempo or speed of activities or the pace that controls the start and end of activities. If an entity in an interinstitutional project is out of sync with the macro pacer, it can have disastrous effects on the project. When organizations involved in an inter-institutional project continue to operate at different cycles or rhythms, this can lead to confusion and conflict affecting collaboration. Therefore, an understanding of the importance of entrainment would be of value to project managers involved in inter-institutional projects.

Thoms and Kerwin point out that "people primarily have different time orientations toward the past, the present or the future" [47]. While each time orientation has its strengths and limitations, different tasks may require a unique time orientation. "This suggests that different projects and different stages of projects require different temporal alignments" [47]. Although Thoms and Kerwin's suggestions are directed towards project leaders, they would be equally applicable to project managers who often take up a leadership role in guiding projects towards their goals. Thoms and Kerwin also propose that a future orientation is particularly useful when the project is dynamic and changing; a present orientation helps in focusing on day-today issues leading to high quality; work while a past orientation helps in using the history of the project or organization, or past decisions or behaviors, and trends in the industry. There are also issues in following one dominant orientation. For example, future orientation could overlook past accomplishments, present orientation could lead to micromanaging and neglecting the big picture while a past orientation could lead to being blindsided to evolving day-today problems leading to a bigger problem. Thoms and Kerwin recommend that as "projects are often very complex, a variety of time orientations will be required during the course of each" [47].

Remington and Pollack [48] point out that temporal complexity occurs in projects that experience severe contextual changes in their environmental conditions. They cite examples of temporal complexity in private sector projects such as mergers and acquisitions or where there is a leadership change, as well as in public sector projects affected by changes in government or legislation. They also point out that temporal complexity can occur in projects with long durations, as is often found in defence projects. They suggest that managing a temporally complex project could challenge the normal ways of doing projects as it requires project managers to be competent in "careful timing of delivery and an approach to positioning deliverables that accounts for multiple possible outcomes and an ongoing 
sensitivity to where the problem areas are likely to occur" [48].

The temporal aspects of projects are also discussed in the literature dealing with projects as a class of temporary organizations. Lundin and Steinthórsson [49] state that time is generally regarded as linear in projects that are often described as having a start and an end. Project plans are often based on a linear concept of time. They point out Gersick's [50] work on teams working in R\&D projects where she found that the project phases were not exactly followed as per plan and even had to be switched around or some phases repeated to complete such projects, suggesting that different temporal dimensions affect the way in which projects are managed. In practice the notion that a project can be isolated from its environment in a permanent organization is difficult to achieve and therefore they urge project managers to coordinate projects from an extended perspective.

\section{"Investigating the projects associated with an organization thus involves answering questions about where the projects come from (their origin) and what will happen to them when their task is completed, as well as the more obvious question that attaches to projects, namely how they are handled over time" [49].}

The multilevel nature of projects as temporary entities, nested in more permanent temporal structures, suggests that different time perspectives and dimensions are necessary to manage projects successfully and to align them with the strategic incentives of the permanent part of the organization. For instance, Bakker and Janowicz-Panjaitan [51], state that people in temporary organizations are more likely to focus on the present. Such an attitude helps with "creativity, innovation and knowledge creation" but it makes it difficult for such organizations to "sediment knowledge into the wider organizational context" [51] and achieve long-term strategic success. The poor dissemination of knowledge in projects and organizations [52] reflects this state of affairs; organizations have great difficulties to learn formally from past knowledge and manifest that knowledge as part of their organizational resource base beyond its tacit existence as embodied and embrained knowing in the organization.

\section{TEMPORAL PLURALITY IN PROJECTS}

Organizational time perspectives cover a wide array of topics, most of which are illustrated in dualisms (e.g. event time versus clock time, cyclical time versus linear time). In line with Artto et al.'s [53] argument, the MOS literature demonstrates that temporal issues take place on multiple levels of organizations, both internal and external [18]. The increase in time-related management vocabulary, such as just-in-time, time-to-market, and timing, support this argument and reflect the growing awareness of time as an important organizational concept, especially in dynamic, unpredictable business environments [32, 54]. The multiplicity of temporal dimensions therefore affects the daily work when managing organizational operation, meaning that the social actor has to juggle the existing temporal perceptions in his or her context.
Historically, project management has promoted planning and carrying out projects in a prescriptive mode, in which extensive planning is used to address (temporal) uncertainty $[55,56]$. However, the assumption of schedule management methods is that the functionality of a finished project is known at the start of the project. Hällgren and Lillieskold [56] argue that project management has paid little attention to deviations that have a small impact and focuses on situations that have a large impact. However, these (temporal) deviations, if not managed well, can lead to significant problems over time. Hence, it is important to focus on the underlying practices that allow managers to realize a synthesis of temporal heterogeneity. Many scholars $[18,32,39]$ identify improvisation as the process through which the aforementioned dichotomies are expressed in a non-dualistic fashion as a temporal tandem. In the same vein, practice studies are not concerned with resolving existing dualism; instead, the focus is on the workability in practice. Consequently, improvisation is not a solution for the existing dichotomies; it is, rather, a lens that allows us to relate and coordinate the existing debates in order to provide temporal guidance to project managers and researchers.

\section{IMPROVISATION}

While improvisation has been a topic of interest in the MOS literature, it has only recently found its way into the world of projects. Due to a shift in project management from its "planning and prescriptive mode" [55] towards a behavioral form of managing projects, improvisation has gained prominence in the last decade [55, 57, 58]. Improvisation often refers to the metaphor of jazz music as a free-flowing and completely flexible way of doing. In a similar way, the project management literature describes improvisation as an experimental, ground-breaking and flexible activity that transcends the organizational structures to make it work, with a focus on improvising project managers [59, 60]. Many (project) managers, however, might find it hard to relate to this notion of improvisation, as they are restrained by a regime of hard performance measures that do not allow for experiments in a similar way to jazz musicians who can follow purely creative instincts.

In order to portray improvisation as more of an everyday way of acting and doing, rather than as an exceptional phenomenon, scholars have recently used practice theory to make sense of improvisation in a way that is meaningful to the practitioner [61-64]. This (revised) form of improvisation illustrates improvisation as the kind of action that is employed when all other alternatives are exhausted [64]. It must be regarded as a reactive form of practice that happens when plans or structures are inaccurate or fail to deliver the expected results but that cannot be completely detached from temporal structure. In this reactive sense, improvisation can be seen as a necessary mundane action to keep the project on track since the modern reality of projects is increasingly characterized by terms such as ambiguity, unpredictability and uncertainty.

Practical improvisation must be understood as a continuous process of reciprocal thinking and action towards a projected future outcome [64], which is achieved by making sense of complex and equivocal experiences and applying this to the situation at hand. Hence, improvisation 
based on past experiences occurs, which constantly evolves through the present action in a particular context. Put simply, improvisation is about recognizing the old, but seeing it as new [64], and thus combines (and collapses) different temporal dimensions to bridge the temporal plurality within projects. The concept of improvisation denies dualities such as planning (future) versus action (present), where the manager first chooses some management model and then applies it mindlessly to real-life scenarios, but instead acknowledges that plans are starting points for all of our actions. In that sense, improvisation does not deny the importance of plans; it is, however, more concerned with the meaningful action that occurs when planning fails and managers try to successfully manoeuvre the project through a sea of complexity [64]. In terms of temporal complexity, the following question remains unanswered: how does practical improvisation help project managers to successfully deliver a project?

\section{LINKING IMPROVISATION AND TIME}

Human beings construct time socially, while time simultaneously shapes our everyday social life. Clocks, seasons and holidays provide a secure temporal structure that allows us to securely engage in our daily practices and routines. In the same way, multiple time perspectives constitute projects and their daily operations for a similar reason. Temporal tools such as deadlines, lifecycles and Gantt charts help project managers to organize present project activities to successfully deliver the projected outcome in the future. However, just like our social world, projects face multiple temporal dimensions including the aforementioned dualisms. Unaligned times lead to unsynchronized project operations, which pose a threat to achieving the required product. The successful project manager therefore develops an adequate structure - in the form of project plans and other necessary documentation that accounts for all eventualities and contingencies in the future. However, the chances that something may go wrong in an increasingly complex project environment are quite high. Hence, we propose that improvisation is a means of handling the breakdown of the temporal structure as it allows us to transcend the traditional dualities.

In line with Crossan et al. [32], we perceive improvisation as a "practical process through which individuals and groups experience and deal with the complex demands of time" [32]. We further believe that improvisation is much more far-reaching than this in projects. Project plans attempt to account for the different time perspectives and dimensions and therefore provide a temporal structure. Improvisation is a mundane part of our daily work life that is both reactive and proactive [64]. Crossan et al. [32] describe the proactive aspect where improvisation is used to plan and coordinate the different temporal solutions, mainly in regards to the abovementioned dichotomies. Project management is a process-driven undertaking and therefore (often) relies on its guiding principles, which make the proactive improvisation of clock and event time and/or cyclical and linear time indispensable. However, the reactive component of improvisation is of equal importance as it focuses on when the pre-planned structure breaks down. Since projects become increasingly complex, the accuracy to predict all future actions is decreasing. Hence, the ability of project managers to adapt the timing of their activities to unanticipated events is critical for a firm's performance [65]. This adds another dimension to the temporal skillset required of a project manager, since most people exhibit a preferred temporal orientation $[31,66$, 67].

\section{HOW DOES IMPROVISATION HELP PROJECT MANAGERS TO MANAGE PROJECTS SUCCESSFULLY?}

Naturally, people have a certain time orientation with an emphasis on either past, present or future [67]. At the same time, organizations have a certain time orientation based on which they structure and plan their work activities. Paradoxically, while a project is often used as a strategic vehicle to achieve a long-term organizational goal situated in the future, the actual project work is situated in the present. Blount and Janicik [65] argue that employees are more efficient in work environments that match their personal time orientation. In our case, that would imply that presentoriented people should work in projects, while futureoriented people should work in the strategic department of an organization. It is, however, questionable if a fit between the organizational and individual time orientation is practicable, since the line between the different temporal components is not as clear-cut as described in the literature [26]. Furthermore, temporal skills are only one of many different talents a successful project manager must possess. Hence, it might be more practical to engage people with a capability to adapt different temporal orientations, which brings us back to improvisation.

Achieving a perfect temporal fit between an organization and its employees appears to be an impractical task. Besides, there are numerous internal and external levels of organizational life that then have to be accounted for. It appears to be more suitable to argue that the individual project manager has to be able to synchronize the different temporal orientations, especially when the pre-given structure breaks down. This is done through improvisation. Improvisation, in that sense, aligns the different rhythms and cycles between the project, organizations and environment [32]. Since not everyone has this form of temporal intelligence, it is necessary that project managers show a form of temporal leadership in which they "entrain their organizations to technology and competitive cycles, manage across multiple time frames, and create temporal architectures for their organizations" [2].

\section{CONCLUSION}

Project management practitioners and researchers have an interest in finding effective ways of dealing with the variety of and complexity in projects. While a great deal of research has been reported in the project management literature as dealing with these issues, very little has been discussed about the understanding and use of temporal skills in the reported research. The literature in organizational studies has begun to pay importance to the use of temporal skills to deal with uncertainty and complexity in permanent organizations. Projects are often regarded as temporary 
organizations and therefore it is surprising that the project management literature has not placed sufficient importance on discussions of the use of temporal skills for project managers: its overly prescriptive and rationalistic orientation probably explains the bias.

The authors believe that knowledge of the three temporal dimensions could be useful for project managers to deal with variety and complexity. These are: understanding the difference between clock time (chronos) and event time (kairos), linear and cyclical time and the effects of entertainment on interrelated projects. Gaining temporal skills will also strengthen the capacity of project managers to improvise. Recent literature in project management has also recommended that project managers learn to improvise to deal with the difficult situations they face in projects.

We propose that temporal structuring and adjusting in projects occurs on the basis of improvisation as part of the project manager's everyday practices. This emphasizes two aspects: the temporal intelligence of the organizational actor and the importance of context-dependent improvisation, which is either proactive or reactive. The project manager's temporal skills allow him/her to create and align temporal conditions in various aspects, including his/her personal time orientation. Using a practice perspective for our examination of time implies that humans shape, as they are being shaped by, temporal structures.

As discussed, project managers create deadlines, plans and lifecycles, while their actions are simultaneously influenced by the created temporal corpus. Orlikowski and Yates [26] describe the project manager's potential to reinforce and alter temporal structure as temporal reflexivity. Improvisation plays an important role in this temporal reflexivity as it explains the proactive alignment of the temporal dimensions and perspectives as well as the reactive synchronization of other temporal aspects in projects. While time is a difficult concept to research due to the multiplicity of angles and lack of measurement $[19,32]$, it is still vital to understand the influence and effects time has on organizational life. Especially in project management, there is a void to be filled in regards to temporality research that can provide us with meaningful insights for theory and practice.

Implications follow for project managers and project organizations [44]: Since projects differ, they cannot be seen as identical entities, thus should be analyzed, managed and organized differently, depending on the particular context, implying vertical as well as horizontal integration of practices, processes and performance criteria. Vertical integration refers to the alignment between the permanent and temporary parts of the organizations, where goals are often misaligned (i.e., long-term vs short-term) Horizontal integration, on the other hand, refers to the different time dimensions that occur within a project itself (i.e., cyclical $v s$ linear), which need to be managed and addressed. Moreover, projects are dynamically evolving entities and should be analyzed, managed and organized differently depending on their phases and focal processes. The concept of improvisation plays an important role here as it refers to the practical process through which project teams experience and deal with the multiple pluralities, perception and demands of time organizations [32]. In other words, the improvisational project manager is able to align different temporal dimensions and thus orchestrate the plurality of projects.

\section{CONFLICT OF INTEREST}

The authors confirm that this article content has no conflict of interest.

\section{ACKNOWLEDGEMENTS}

Declared none.

\section{REFERENCES}

[1] Roe RA, Waller MJ, Clegg SR, Eds. Time in Organizational Research: Approaches and Methods. London: Routledge 2008.

[2] Ancona DG, Goodman PS, Lawrence BS, Tushman ML. Time: A New Research Lens. Acad Manage Rev 2001; 26(4): 645-63.

[3] George JM, Jones GR. The role of time in theory and theory building. J Manage 2000; 26(4): 657-84.

[4] Mitchell TR, James LR. Building better theory: Time and the specification of when things happen. Acad Manage Rev 2001; 26(4): 530-47.

[5] Bergh DD. Watch the time carefully: The use and misuse of time effects in management research. J Manage 1993; 19(3): 683-705.

[6] McGrath JE, Kelly JR. Time and human interaction: Toward a social psychology of time. New York, NY: Guilford Press 1986.

[7] Avolio BJ. Promoting more integrative strategies for leadership theory-building. Am Psychol 2007; 62(1): 25-33.

[8] Eaton LG. Personality and emotional experience in daily life. In: Shohov SP, Ed. Advances in Psychology Research. Hauppauge, NY: Nova Science Publishers 2004, pp. 101-39.

[9] Fried Y, Slowik LH. Enriching goal-setting theory with time: An integrated approach. Acad Manage Rev 2004; 29(3): 404-22.

[10] Mathieu JE, Schulze W. The influence of team knowledge and formal plans on episodic team process-performance relationships. Acad Manage Rev 2006; 49(3): 605-19.

[11] PMI. A Guide to the Project Management Body of Knowledge (PMBOK Guide) $5^{\text {th }}$ ed Newtown Square, Pennsylvania: Project Management Institute 2013

[12] Turner JR. The handbook of project-based management. London: McGraw-Hill 2009.

[13] Bluedorn AC, Denhardt RB. Time and organizations. J Manage 1988; 14(2): 299-320.

[14] Mead GH. Mind, Self and Society: from the Standpoint of a Social Behaviourist. In: Morris CW, Ed. Chicago, IL: Chicago University Press 1934.

[15] Schütz A. The phenomenology of the social world. In: Wild J, Ed. Evanston, IL: Northwestern University Press 1967.

[16] Butler R. Time in Organizations: Its experience, explanations and effects. Organ Stud 1995; 16(6): 925.

[17] Cyert R, March J. A behavioral theory of the firm. Englewood Cliffs, NJ: Prentice Hill 1963.

[18] Cunha MP. Organizational time: a dialectical view. Organization 2004; 11(2): 271

[19] Roe R. Perspectives on time and the chronometric study of what happens in organizations. London: Routledge 2007.

[20] Lee H, Liebenau J. Time in organizational studies: Towards a new research direction. Organ Stud 1999; 20(6): 1035-58.

[21] Das TK. Time: The hidden dimension in strategic planning. Long Range Plan 1991; 24(3): 49-57.

[22] Meyer JW. Globalization sources and effects on national states and societies. Int Sociol 2000; 15(2): 233-48.

[23] Banerjee S, Carter C, Clegg S. Managing globalization. In: Alvesson M, Bridgman T, Wilmott H, Eds. The Oxford Handbook of Critical Management Studies. Oxford: Oxford University Press 2009. pp. 186-212.

[24] Goddard R. Time in organizations. J Manage Develop 2001; 20(1): 19-27.

[25] Orlikowski W, Yates J. It's about time: An enacted view of time in organizations. Organ Sci 1999; 13(6): 684-700. 
[26] Orlikowski W, Yates J. It's about time: Temporal structuring in organizations. Organ Sci 2002; 13(6): 684-700.

[27] Taylor FW. The Principles of Scientific Management. New York, NY: Harper \& Row 1911.

[28] Jaques E. The form of time: Crane, Russak 1982.

[29] Starkey K. Time and work: A psychological perspective. Time Work Organ 1989: 57-78.

[30] Clark P. A review of the theories of time and structure for organizational sociology. Rese Socio Organ 1985; 4: 35-79.

[31] Levine R. A geography of time. New York: Basic Books 1997.

[32] Crossan M, Cunha MPe, Vera D, Cunha J. Time and organizational improvisation. Acad Manage Rev 2005; 30(1): 129-45.

[33] Hassard J. Images of time in work and organization. Handb Organ Stud 1996; 581: 598.

[34] Deroy X, Clegg S. Back in the USSR: Introducing Recursive Contingency Into Institutional Theory. Organization Studies. 2014;first published online 19 Septembere 2014: DOI: 10.1177/01 70840614544556

[35] Cavendish R. Women on the Line. Routledge \& Kegan Paul London 1982.

[36] Ancona D, Chong CL. Entrainment: Pace, cycle, and rhythm in organizational behavior. Res Organ Behav 1996; 18: 251-84.

[37] McGrath JE, Rotchford NL. Time and behavior in organizations. Res Organ Behav 1983; 5: 57-101

[38] Ancona D, Chong CL. Cycles and synchrony: The temporal role of context in team behavior. Elsevier Science/JAI Press 1999.

[39] Bluedorn A. The human organization of time: Temporal realities and experience. Stanford, CA: Stanford Business Books 2002.

[40] Brown SL, Eisenhardt KM. Competing on the edge: Strategy as structured chaos. Boston, MA: Harvard Business Press 1998.

[41] Pitsis TS, Clegg SR, Marosszeky M, Rura-Polley T. Constructing the Olympic Dream: A Future Perfect Strategy of Project Management. Organ Sci 2003; 14(5): 574-90.

[42] IPMA. IPMA Competence Baseline. IPMA, Njikerk 2006

[43] Atkinson R. Project management: cost, time and quality, two best guesses and a phenomenon, its time to accept other success criteria. Int J Proj Manage 1999; 17(6): 337-42.

[44] Dille T, Söderlund J. Managing inter-institutional projects: The significance of isochronism, timing norms and temporal misfits. Int J Proj Manage 2011; 29: 480-490

[45] Schultz M, Hernes T. A temporal perspective on organizational identity. Organ Sci 2013; 24(1): 1-21.

[46] Rämö $\mathrm{H}$. Doing things right and doing the right things Time and timing in projects. Int J Proj Manage 2002; 20(7): 569-74.

[47] Thoms P, Kerwin JJ. Leadership of project teams. In: Morris PWG, Pinto JK, Eds. The Wiley Guide to Managing Projects: Wiley Online Library 2007; pp. 1014-32.

[48] Remington K, Pollack J. Tools for complex projects. Surrey, England: Gower Publishing Company 2007.
[49] Lundin RA, Steinthórsson RS. Studying organizations as temporary. Scand J Manage 2003; 19(2): 233-50.

[50] Gersick CJG. Time an transition in work teams: Toward a new model of group development. Acad Manage J1988; 31(1): 9-41.

[51] Bakker RM, Janowicz-Panjaitan M. Time matters: The impact of 'temporariness' on the functioning and performance of organizations. In: Kenis P, Janowicz-Panjaitan M, Cambre B, Eds. Temporary organizations: Prevalence, logic and effectiveness. Northampton, MA: Edward Elgar Publishing 2009, pp. 121-41.

[52] Bakker RM, Boroş S, Kenis P, Oerlemans LAG. It's only temporary: Time frame and the dynamics of creative project teams. Br J Manage 2012; DOI: 10.1111/j.1467-8551.2012.00810.x.

[53] Artto K, Kulvik I, Poskela J, Turkulainen V. The integrative role of the project management office in the front end of innovation. Int $\mathrm{J}$ Proj Manage 2011; 29(4): 408-21.

[54] Stalk G, Hout TM. Competing against time: how time-based competition is reshaping global markets. Free Press: USA 1990.

[55] Leybourne SA. Improvisation and agile project management: a comparative consideration. Int J Managing Proj Bus 2009; 2(4): 519-35.

[56] Hällgren M, Lillieskold J, Eds. Three Modes of Deviation Handling: Coping with Unexpected Events in Project Management 2006: IEEE.

[57] Leybourne S, Sadler-Smith E. The role of intuition and improvisation in project management. Int J Proj Manage 2006; 24(6): 483-92.

[58] Leybourne S. Project management and high-value superyach projects: An improvisational and temporal perspective. Proj Manage J 2010; 41(1): 17-27.

[59] Gallo M, Gardiner PD. Triggers for a flexible approach to project management within UK financial services. Int J Proj Manage 2007; 25(5): 446-56.

[60] Leybourne SA. Managing change by abandoning planning and embracing improvisation. J General Manage 2006; 31(3): 11-29.

[61] Tsoukas H, Chia R. On organizational becoming: Rethinking organizational change. Organ Sci 2002; 13(5): 567-82.

[62] Purser R, Petranker J. Unfreezing the Future. J Appl Behav Sci 2005; 41(2): 182.

[63] Feldman MS, Orlikowski WJ. Theorizing practice and practicing theory. Organ Sci 2011; 22(5): 1240-53.

[64] Dehlin E. The Flesh and Blood of Improvisation. Trondheim: Norwegian University of Science and Technology 2008.

[65] Blount S, Janicik GA. When plans change: Examining how people evaluate timing changes in work organizations. Acad Manage Rev 2001: 26(4) 566-85.

[66] Zimbardo PG, Boyd JN. Putting time in perspective: A valid, reliable individual-differences metric. J Pers Soc Psychol 1999; 77(6): 1271

[67] Zimbardo PG, Boyd J. The time paradox: The new psychology of time that will change your life: Free Press: USA 2009. 